\title{
Interaction of biotic and abiotic factors and polyphenolic content of grades of grape
}

Vlasov V. ${ }^{1}$, Levytskyj A. ${ }^{2}$, Muljukina N. ${ }^{3}$, Grytsuk A. ${ }^{4}$, Khodakov I. ${ }^{5}$, Kovaljova I. ${ }^{6}$, Geretskyj R. ${ }^{7}$

1, 3, ${ }^{6}$ NSC «V.E. Tairov Institute of viticulture and winemaking» of NAAS, 40-richchia Peremohy Str., 27, Taitovo, 65496, Odessa, Ukraine, ${ }^{2,5}$ Institute of stomatology and maxillofacial surgery of NAMS of Ukraine, Rishelyevska Str., 11, 65000, Odessa, Ukraine, ${ }^{4}$ Gomel medical university, Lange Str., 5, 246000, Gomel, Belarus, 7 Odessa state agrarian university, Kanatna Str., 99, 65012, Odessa, Ukraine; e-mail:

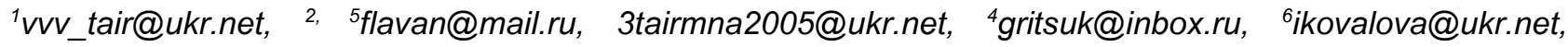
7geretskiy@gmail.com

The purpose. To study polyphenolic content of grades of grape of new selection in a slit of determination of dependence between polyphends content, genetic origin and resistance against fungous diseases of paleocrystic wood of grape. Methods. Chromatographic - for determination of content of separate groups of polyphenolic joints of grape, field - for determination of levels of damage of leaf apparatus of grape caused by esca; mathematical statistics - for research of connection between extent damage by esca of grape and the content of polyphenolic joints. Results. Presence is shown of dependence between genetic origin of grape of grades created in NSC «V.E. Tairov Institute of viticulture and winemaking» and polyphenolic content of grape and wine. Presence at genome of technical grades of grape of genetic material Vitis amurensis and Vitis rupestris increases the content of common polyphenols in must. It is shown that weaker developing process of esca symptoms matches to a lot of polyphenolic joints from groups of flavonols, flavanones, flavones, anthocyans and to the greater total content of polyphenols. The analysis of the content of separate joints has shown that healthy (asymptomatic) bushes are characterized by the greater content of chlorogenic acid while sick bushes surpass healthy plants under the content of quercetin. On the basis of assessment of main groups of polyphenolic joints of plants of grape with different extent of esca injury and at the simultaneous analysis of meteorological factors of a year the assumption concerning the potential mechanism of influence of moisture on developing process of esca symptoms in grape and presence of connection between hydric factor and level of polyphenolic joints of grape is put forward. Conclusions. The detected dependences can become a basis for development of a method of early diagnostics of resistance of grape to fungous diseases during selection. Data under the content of polyphenolic joints of grape and wine will be used for creation of database antioxidant properties of wines.

Key words: grape, origin of grades, polyphenolic joints, quercetin, catechins, rutin, esca of grape.

$$
\text { https://doi.org/10.31073/agrovisnyk201811-09 }
$$

Polyphenolic compounds of grapes are actively studied due to the diversity of their functions in the plants, their biological and nutritional value.

In agriculture, these compounds are known due to their effect of increasing the plant's resistance to diseases, first of all - diseases caused by phytopathogenic fungi.

Analysis of recent research and publications. Researchers from a number of viticultural countries have found that grapevine polyphenols increase resistance to downy an powdery mildew; in recent years, research has focused on the study of the polyphenols role in the protection of grapevine from trunk diseases, which are currently one of the most dangerous groups of grapevine diseases [1, 2, 3, 4].

Numerous studies have shown that the content of different polyphenols groups and, accordingly, resistance to grapevine fungal diseases is associated with the genetic origin of the variety. In general, most of these studies show that the presence in the genome genetic material of Vitis rupestris and Vitis amurensis positively affects positively on polyphenols content and, accordingly, resistance to grapevine fungal diseases [1].

A number of studies on grape polyphenols are also aimed to identification the effects of environmental factors on their levels in grapevine [5]. 
Thus, the factors that affect the level of the polyphenols of the grape plant, primarily include genetic, pathological and abiotic ones.

Increasing levels of polyphenolic compounds in a grape plant, in turn, can be used in several directions. The most interesting from the medical point of view are the antioxidant properties of polyphenols, especially such compounds as resveratrol, catechins, quercetin and several others. These substances have cardioand onco-protective properties, anti-inflammatory and immunomodulating ones, they can be used for combating the effects of radiation, etc. $[6,7,8]$.

Consequently, increasing the grape polyphenols content gives the opportunity to choose new, better sources for the manufacture of food products with therapeutic and prophylactic properties and biologically active supplements.

Scientists of the NSC «Tairov Research Institute of Viticulture and Wine-Making» together with specialists of the Institute of Stomatology and Maxillofacial Surgery have done numerous studies of the grapevine polyphenol complex. The correlation between the resistance of new breeded grapevine varieties to fungal diseases and increasing of polyphenols content has been shown [9, 10].

Insufficient level of polyphenolic complex of new breeded grapevine varieties research does not allow the full use of this information to detect links between the genotype (the origin of the variety), the content of the main groups of polyphenols and the stability of grapes to fungal diseases.

Using this approach will enable:

- to develop a method of early genotypes resistant to fungal pathogens screening in breeding of wine, table varieties and rootstocks with the help of biochemical markers;

- to find out the best sources, phenolic compounds rich, for obtaining food products with biological activity (grape and wine for ampelo-eno treatment) and the production of BASs on the basis of grapes;

- use the information obtained to create a database of antioxidant potential of domestic Ukraina wines.

Goal. To investigate the polyphenolic composition of grape varieties of a new breeding in the context of determining the relationship between their content, genetic origin and resistance to grapevine trunk I diseases.

Materials and methods of research. The material for the study were varieties of breeding by NSC «Tairov Research Institute of Viticulture and Wine-Making»", wine, table cultivars and rootstocks. The following methods - chromatographic - to determine the content of grapevine polyphenolic compounds groups, field determining the levels of grapevine leaves damage by esca; the correlation analysis using the Microsoft Office Statistical Analysis Package have been used.

\section{Research results.}

\section{Influence of the genotype on the grapevine polyphenolic compounds content}

To study the effect of genotype on the grapevine polyphenolic compounds content a number of newly breeded varieties of "Tairov Research Institute of Viticulture and Wine-Making»", the part of Vitis species genotypes was estimated (Table 1).

Table 1. Part of Vitis species genotypes and polyphenolic content in must of wine varieties, breeded by NSC "Tairov Research Institute of Viticulture and Wine-Making»",

\begin{tabular}{|l|c|c|c|c|}
\hline Variety & $\begin{array}{l}\text { Vitis vinifera geno- } \\
\text { type, \% }\end{array}$ & $\begin{array}{l}\text { Vitis rupestris } \\
\text { genotype, \% }\end{array}$ & $\begin{array}{l}\text { Vitis amurensis } \\
\text { genotype, \% }\end{array}$ & $\begin{array}{l}\text { Total polyphenols } \\
\text { in must, mg/dm 3 }\end{array}$ \\
\hline Aromatnij & 76 & 7 & - & 376 \\
\hline Muscat of Odessa & 76 & 7 & 12,5 & 681 \\
\hline Zagrej & 75 & 13 & 12 & 601 \\
\hline Iscorka & 88,3 & 5,1 & 3,2 & 549 \\
\hline Tairov's Ruby & 63 & 32 & - & 590 \\
\hline Odessa black & 100 & - & - & 1650 \\
\hline
\end{tabular}

Although this approach is somewhat apppproximate, since important is not the calculated part of the genotype, but structural genes, which are responsible for the synthesis and metabolism of polyphenolic 
compounds, some regularities can be traced even with a simplified version. As can be seen from Table 2, Muscat of Odessa and Zagrej varieties, with a total proportion of Vitis rupestris and Vitis amurensis genotypes 20 and more percent, are characterized by the highest levels of polyphenols content in the must. This index is slightly less for the Aromatnij and Tairov's Ruby varieties, although in Tairov's Ruby part of the other species genotypes exceeds $30 \%$, but this proportion belongs only to the Vitis rupestris spesies. On the basis of this, it can be assumed the existence of Vitis amurensis genotype unfluence on the content of grape polyphenols.

The high level of polyphenolic compounds in the Odessa Black variety, which is pure Vitis vinifera, requires further discussion. However, one of the parents of the Odessa Black is the Cabernet Sauvignon variety, which contains an abnormally high number of polyphenolic compounds, but is susceptible to fungal infection. This issue is currently being discussed in the environment of foreign researchers of the grapevine polyphenolic complex, but the answer to it is possible only in the case of a detailed description of the main groups of polyphenols and analysis of their metabolic pathways.

Analysis of the connection between the polyphenol complex of grapes and the resistance to fungal diseases of perennial grape wood (on the esca example)

To study the relationship between the resistance of grapes to fungal diseases and the content of the main groups of polyphenols, we analyzed the polyphenolic composition of grapevine plants from 3 groups of the esca symptoms development on perennial wood - healthy asymptomatic plants, plants with an affection of $50 \%$ crowns and plants with an affection of $50 \%$ of the crown (Figure 1).

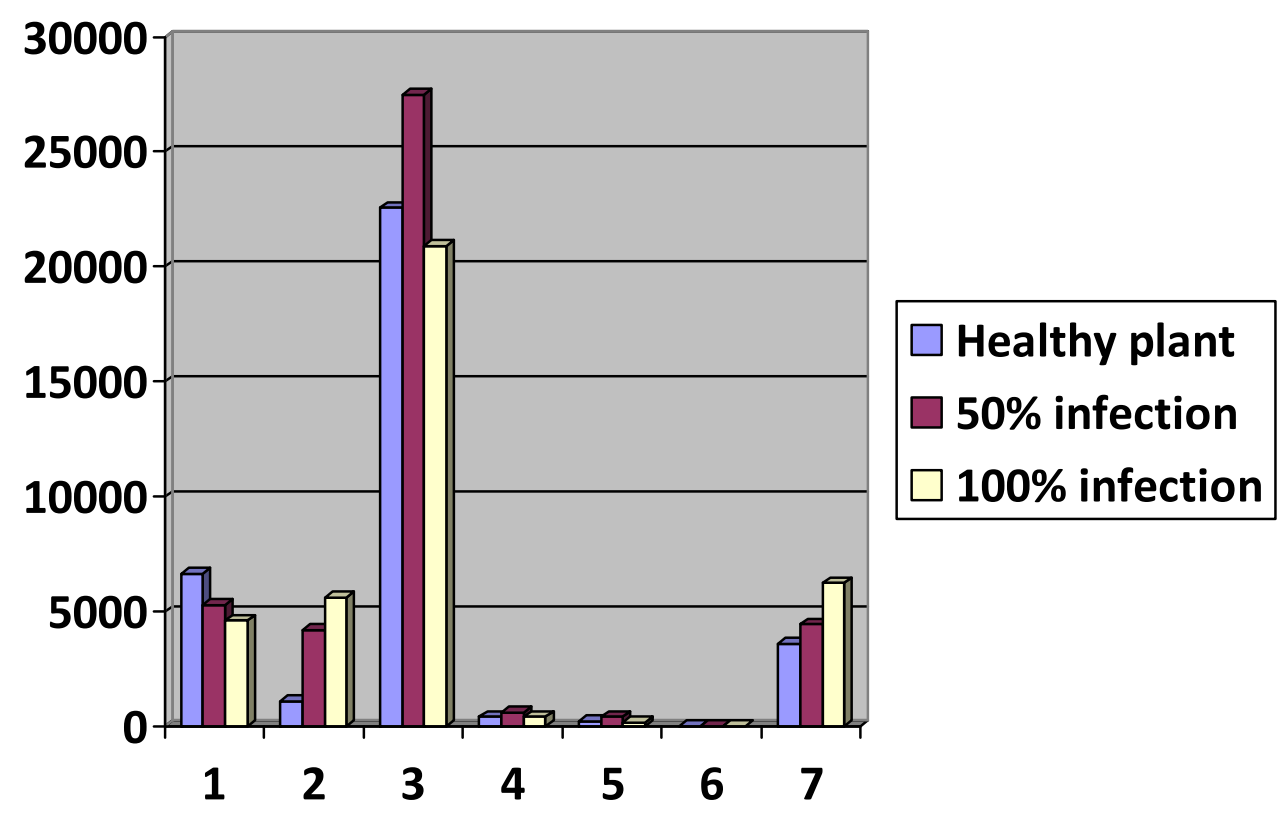

Fig. 1. Influence of various degrees of the esca infection on the content of groups of polyphenolic compounds ( $\mathrm{g} / \mathrm{g}$ dry leaves) 1 - phenolic acids, 2 - catechins, 3 - flavonols, 4 - flavonones, 5 - flavones, 6 anthocyanins, 7 - undifferentiated

As shown in Figure 1, group $2(-50 \%$ of affection) predominates in the content of flavonols, flavanones, flavones, anthocyanins and total phenol content - 5 groups out of 8 examined (not shown) compared to plants of group 3 ( $100 \%$ of lesions shoots and leaves by esca) - perhaps because of this level of affection is the course of the most active metabolic processes of confrontation of the infection. Thus, less manifestation of the symptoms corresponds to a greater number of polyphenolic compounds from the groups of flavonols, flavanones, flavones, anthocyanins and total polyphenols.

In the above-mentioned 3 groups of plants with different levels of manifestation of symptoms, also identified individual polyphenolic compounds (Figure 2). 


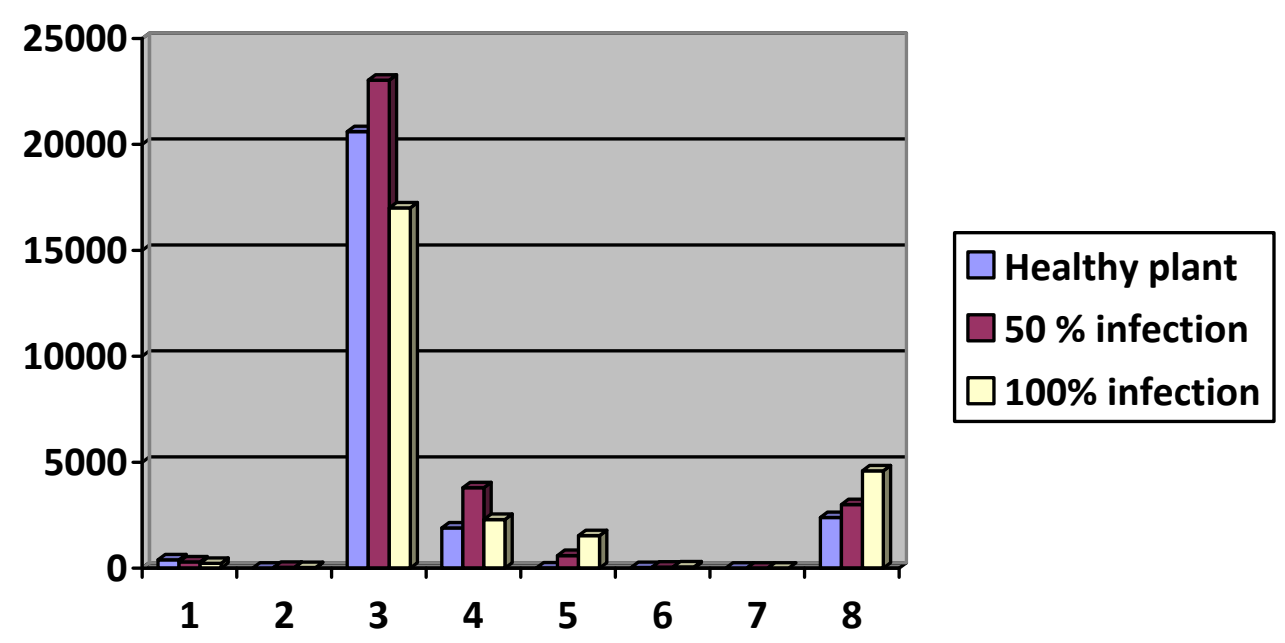

Fig. 2. Influence of various degrees of esca damage on the polyphenolic compounds content ( $\mathrm{g} / \mathrm{g}$ of dry leaves) 1 - chlorogenic acid, 2 - catechin, 3 - glucuronide of quercetin, 4 - rutin, 5 - quercetin, 6 naringen, 7 - luteolin, 8 - substance A.

Fig. 2 shows that healthy plants have a higher content of chlorogenic acid than two other experimental groups of plants. The diseased bushes with $100 \%$ lesion are dominated by 2 other groups in content of quercetin and naringenin, luteolin and substance A. Group 2 - 50\% of affection predominates in catechin, quercitin glucuronide and routine content.

Differences in the content of groups and individual polyphenolic compounds between healthy and necrotized tissues were also investigated in the experimental groups of plants that differed in the manifestation of symptoms (Figures 3 and 4).

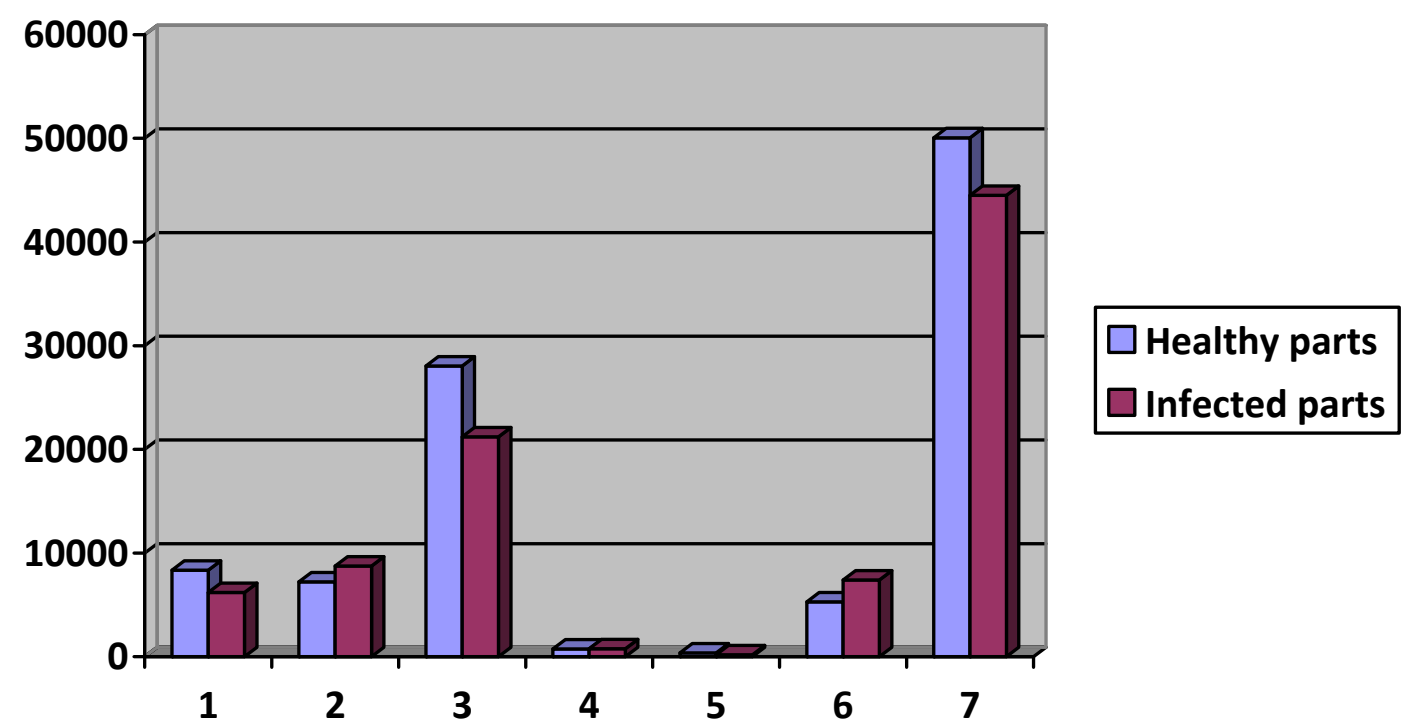

Fig. 3. Comparative analysis of the polyphenolic compounds content in visually healthy and necrotized tissue areas ( $\mathrm{g} / \mathrm{g}$ of dry leaves).

1 - phenolic acids, 2 - catechins, 3 - flavonols, 4 - flavonones, 5 - flavones, 6 - undifferentiated, 7 - the sum of polyphenols

The analysis of the polyphenols content in healthy tissue and in affected leaf areas shows that in healthy tissues a higher concentration of phenolic acids, flavonols, flavones and total polyphenols content. At the same time, the affected sites contain more catechins, flavonones and unidentified polyphenols 


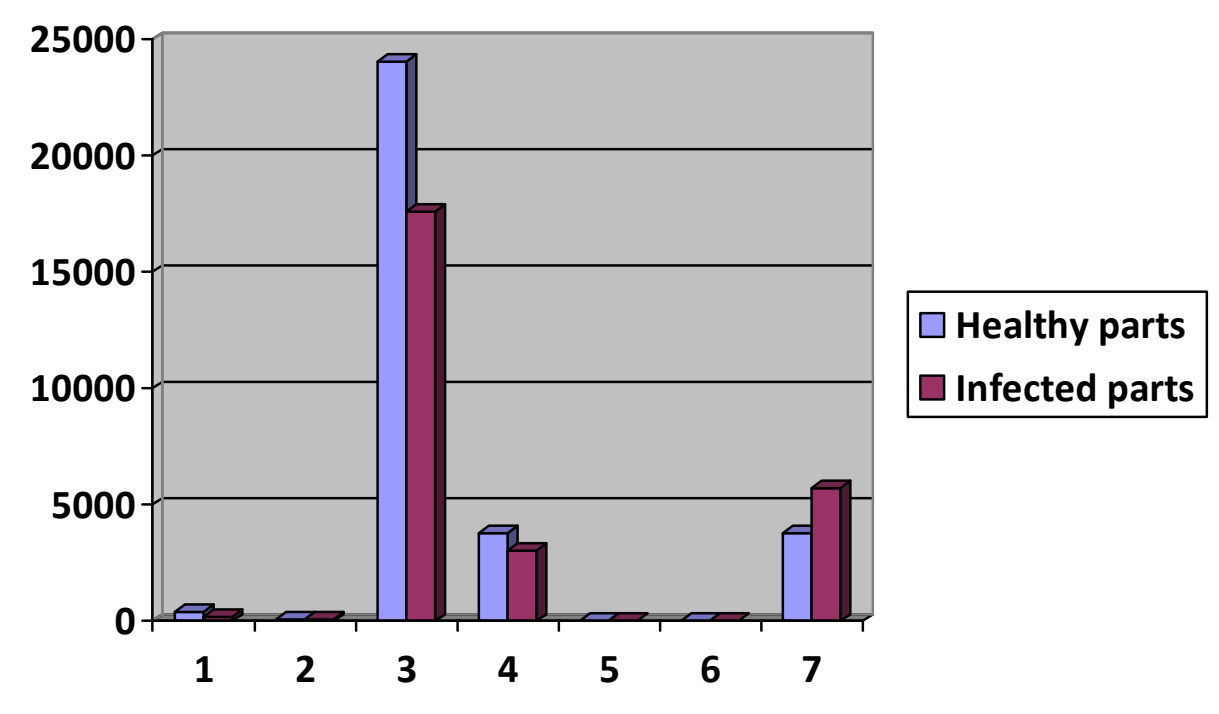

Fig. 4. Influence of various degree of esca damage on the polyphenolic compounds content ( $\mathrm{g} / \mathrm{g}$ of dry leaves) 1 - chlorogenic acid, 2 - catechin, 3 - glucuronide of quercetin, 4 - rutin, 5 - quercetin, 6 - naringenin, 7 - luteolin, 8 - substance $A$.

Analysis of the content of individual polyphenols in healthy tissue and affected areas shows that in healthy tissues a higher concentration of chlorogenic acid, catechin, quercitin glucuronide and routine. At the same time, the tissues of the affected areas have a higher concentration of quercetin, narginin, luteolin and substance A.

The manifestation of the esca symptoms, the content of polyphenols and the potential impact of We did not carry out a purposeful study of the meteorological factors influence on the grape polyphenols content, but the study of the influence of temperature and humidity on the esca symptoms manifestation was accompanied by an analysis of the grape polyphenol complex, therefore, it became possible to draw some preliminary conclusions.

In this study, it was discovered (Muliukina et al., the article is printed) that the meteorological conditions of the year significantly affect the level of grapevine damage by esca. The highest dependence was detected between the increase in precipitation in the period of October-November and the disease manifestation $o$ in the next season of vegetation. The increase in precipitation in the fall causes a decrease of esca symptoms in the next season of vegetation to varying degrees in the Dobrynja rootstock and in the Cabernet Sauvignon variety $(r=0.79$ and $r=0.45$, respectively).

Simultaneous detection of various groups of grape polyphenols content changes (see above) has led to the assumption that the basis of the revealed pattern is the effect of two factors - on the one hand, the greater amount of precipitation reduces the toxic substances concentration, on the other hand - creates better conditions for the biochemical flow processes in cells, including the polyphenols metabolism In turn, a number of metabolic processes, especially those related to polyphenolic compounds, are associated with plant resistance to fungal pathogens and the manifestation of esca symptoms.

Based on the estimation of the main polyphenolic compounds groups of grapevine plants with varying degrees esca symptoms, an assumption is made regarding one of the potential mechanisms of the humidity factor influence on the grapevine esca symptoms manifestation.

We believe that the improvement of metabolic processes due to additional moisture on the background of toxins concentration reducing leads to an increase in the synthesis of polyphenolic compounds, and therefore - better counteraction to the disease.

\section{Analysis of factors that influence the increase of polyphenolic compounds of grapes}

Polyphenolic compounds are a natural component of most plants species including the Vitaceae family, in which they are synthesized by several species, including $\mathrm{V}$. vinifera $\mathrm{L}$. The vast majority of polyphenolic compounds of grapes, in particular stilbenes, are low molecular weight phenolic compounds with 
antimicrobial activity. Under biotic stress, stilbenes act like phytoalexins, a number of grape pathogens induce the synthesis of stilbenes - including gray rot (Botrytis cinerea), downy mildew (Plasmopara viticola) namely, the synthesis of trans-resveratrol and viniferin, both in berries and in the leaves. In this case, resistant genotypes can quickly synthesize a large number of phytoalexins, while susceptible synthesize them slowly and in small concentrations. Thus, the interconnected factors "genotype - influence of the pathogen" affect the content of polyphenolic compounds of grapes. The third group of factors that significantly affects the content of polyphenols in the vine are abiotic factors, including humidity, temperature and UV irradiation.

Attention to the study of these factors has been crocheted since the 70's 80 's, but the degree of their research is different. The largest amount of researches is devoted to the study of the influence of fungal diseases and the origin of grape varieties, to a lesser extent the influence of abiotic factors has been studied.

The state of these factors research is determined by the prospect of practical implementation of the obtained results. It is the genotype and the response to the disease that is an interesting tool for implementing breeding programs and creating a new generation of resistant grape varieties. However, increasing attention to the study of the abiotic factors influence in the last decade due to global climate change, most likely, may become one of the trends of agriculture adaptation to new conditions.

The data we received regarding the influence of genetic, biotic and abiotic factors, analyzed and reflected in the scheme (Fig. 5).

The scheme presents not only the main factors that have a positive effect on the grape polyphenolic compounds content, but also the areas in which it is possible to use this phenomenon.

The first two of them concern the increase in the biological value of food and the manufacture of dietary supplements. It should be noted that overseas researches not only test natural ways to increase the content of polyphenols, but also artificially add them (for example, adding an additional amount of resveratrol to dry red wines) [11].

The second direction concerns mostly genetic selection studies and the use of polyphenolic compounds as markers of resistance or signs of interest that correlates with the resistance of the variety to fungal pathogens.

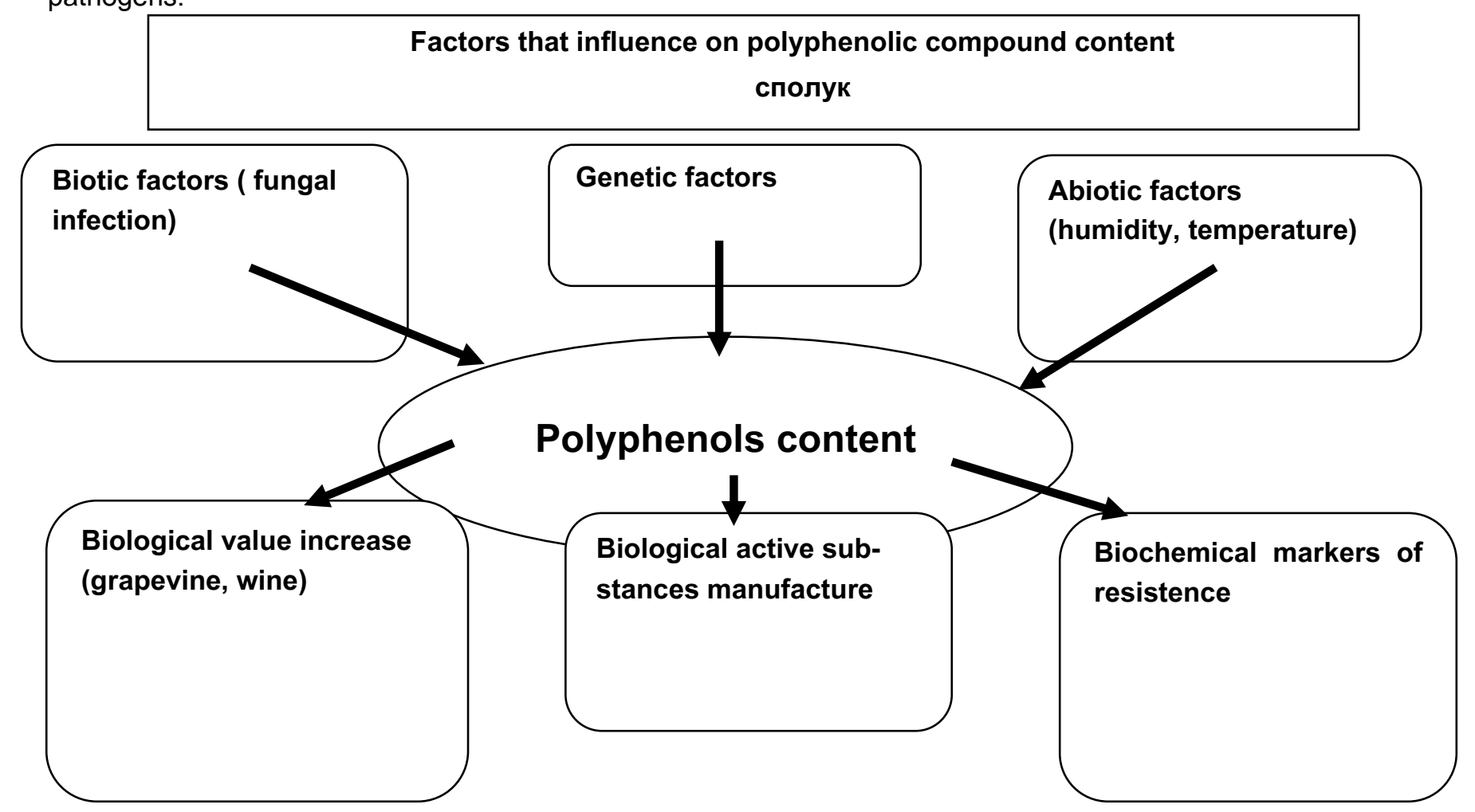

Fig. 5. Ways of increasing of polyphenols contents in grapes and potential directions for their use 


\section{Conclusions}

On the example of grapes selected by NSC "Tairov Research Institute of Viticulture and Wine-Making" shows that the presence in the genome of the wine grape varieties genetic material of Vitis amurensis and Vitis rupestris increases the content of the total phenol in the must. It has been demonstrated that different degrees of esca damage correlates with the levels of grape polyphenols groups, in particular, the less manifestation of the symptoms corresponds to a greater number of polyphenolic compounds from the groups of flavonols, flavanones, flavones, anthocyanins, and a higher total polyphenols content. Analysis of individual compounds has shown that healthy (asymptomatic) bushes have a higher content of chlorogenic acid, while diseased bushes (with 100\% defeat of the leaves by esca) have higher contents of quercetin, naringenin, luteolin and substance A. Based on the evaluation of the main groups of grape polyphenolic compounds in grapevine plants with varying degrees of esca manifectation and the simultaneous analysis of meteorological factors of the year put forward an assumption about the potential mechanism of influence of the humidity factor on esca symptoms manifestation and the presence of a bundle between the humidity factor and the level of polyphenolic compounds of grapes.

Detected dependencies can become the basis for developing the method of early diagnosis of grape resistance to fungal diseases in the breeding processes. Data on the polyphenolic compounds content in grape and wine will be used to create a database of antioxidant properties of wines.

\section{Bibliografy}

1. Bavaresco L., Fregoni C., Van Zeller D.M. et al. (2009). Physiology and Molecular Biology of Grapevine Stilbenes: an update. In Roubelakis-Angelakis, K., Grapevine Molecular Physiology and Biotechnology. Springer. Dordrecht. P. $341-364$.

2. Amalfitano C., Evidente A., Surico G. et al. (2000). Phenols and stilbene polyphenols in the wood of escadiseased grapevines. Phytopathol. Mediterr. 39. P. $178-183$.

3. Calzarano F., D'Agostino V., Del Carlo M. (2008). Trans-Resveratrol Extraction from Grapevine: Application to Berries and Leaves from Vines Affected by Esca Proper. Analytikal Letters. 41(4). P. $649-661$.

4. Del Rio J.A., Gonzalez A., Fuster M.D. et al. (2004). Tyloses formation and changes in phenolic compounds of grape roots infected with Phaeomoniella chlamydospora and Phaeoacremonium species. Phytopathol. Mediterr. 43. P. $87-94$.

5. Teixeira A., Castellarin S., Eiras-Dias J. et al. (2013). Berry phenolics of grapevine under challenging environments. Molecular Sciences. V. 19. Iss. 9. P. 18711 - 18739.

6. Stuard J.A., Robb E.L. (2013). Bioactive Polyphenols from Wine Grapes. Springer. 83 p.

7. Ramprasath V.R., Jones P.J. (2010). Anti-atherogenic effects of resveratrol. Eur J. Clin Nutr. V. 64. P. $660-668$.

8. Gritsuk A.l., Vlasov V.V., Mulyukina N.A., Levitskiy A.P. (2017). Polifenoly vinograda v reshenii problem postradiatsionnykh oslozhneniy. [Grape polyphenols in solving problems of post-radiation complications]. Nauka, zdorov'e i pitanie: materialy Mezhdunar. kongr. Minsk, 6 - 8 iyunya. Minsk. P. 64 - 69. [In Russian].

9. Khodakov I.V., Levitskiy A.P., Makarenko O.A. i dr. (2015). Sostav i soderzhanie polifenolov v list'yakh vinograda sortov Aromatnyy i Odesskiy chernyy ukrainskoy selektsii $v$ letniy i osenniy periody vegetatsii. [The composition and content of polyphenols in the leaves of grape varieties Aromatny and Odessa black Ukrainian selection in summer and autumn vegetation periods]. Fiziologiya rasteniy i genetika. T. 47, No 3. P. 224 - 235. [In Russian].

10. Vlasov V.V., Mulyukina N.A., Kovaleva I.A., Geretskiy R.V. (2016). Stil'beny vinograda kak biokhimicheskaya osnova ustoychivosti $k$ eske. [Stilbene grapes as a biochemical basis for ecology stability.]. Simpozional «Biotehnologii avansate-realizari si perspective " esteconsacrat problemelor ce vizeaza aplicabilitatea metodelor biotehnologice avansate in identificarea genotipurilor valoroase, crearea a noi soiuri de planete cu caractere agronomic pretioase si metode de protective a plantelor. Chisinau. P. 131. [In Russian].

11. Gaudette N.J., Pickering G.J. (2011). Sensory and chemical characteristics of trans-resveratrol fortified wine. Aust. J. Grape Wine Res. V. 117. P. $249-257$. 